de nuevo en 1789 (en la testamentaría de Carlos III), en la «pieza de trucos» del Palacio real madrileño; y lo sería de nuevo en 1794, en 1811 y en 1814 (con erróneas medidas de 31/2 por 31/2 varas), para pasar finalmente al Museo del Prado en 1819 (Inv. $\left.n^{\circ} 1173\right)^{32}$.

En conclusión, tendríamos que pensar en un único lienzo del formato y la composiciones actuales a lo largo de toda su historia, más que en uno más reducido y más apaisado, que pasó por las manos de don Pedro de Arce - que bien pudieran no haber sido las primeras en poseer Las Hilanderas - y después por las de los Duques de Medinaceli, antes de entrar en la colección real del Buen Retiro incluso después del incendio del Alcázar de 1734. Aunque sólo el descubrimiento de nuevos documentos podrá validar estas hipótesis.

FERnANDo Marías Universidad Autónoma de Madrid

\title{
JUAN BAUTISTA MAÍNO Y LA MAGDALENA
}

Es, sin duda, Juan Bautista Maíno uno de los más fieles intérpretes del primer naturalismo, además de uno de los más dotados artistas que trabajaron en Madrid en el primer tercio del siglo XVII. Su obra ha sido estudiada por diferentes autores, intentando explicar su filiación con modelos caravaggiescos en fechas tan tempranas, y sobre todo su modernidad, pues anticipa en el Madrid de los primeros decenios del XVII una manera de entender el arte completamente nueva ${ }^{1}$. Precisamente en su producción el gusto por la sensualidad y la desnudez no pasa inadvertida en sus modelos y este aspecto también presente en la pintura de Anibale Carracci y Guido Reni, no permaneció ajeno en la historiografía artística, pues el propio Jusepe Martínez cuenta que Maíno era discípulo de Carracci y compañero de Guido Reni ${ }^{2}$. Ese gusto por lo inmediato, por lo verosímil y al mismo tiempo vivo, le hace acercarse al cuerpo humano con un atento deseo de verdad más que de santidad.

En este sentido uno de los temas que mayor sensualidad y belleza terrenal concitó fue el de María Magdalena en el desierto. Hace poco tuvimos ocasión de tratar este tema en la exposición que se celebró en el Museo Nacional de San Carlos de México ${ }^{3}$, aportando la fuente que pudo servir a Maíno para la Magdalena penitente conservada en el Museo del Prado, procedente del banco del retablo de Las cuatro pascuas de San Pedro Mártir de Toledo. En ese caso, probablemente la estampa de Lucas Vosterman I sobre composición de Gerard Seghers ${ }^{4}$,

\footnotetext{
${ }^{32}$ Véase ahora Corpus velazqueño, ed. Ángel Aterido Fernández, 2 vols., Ministerio de Educación, Cultura y Deporte, Madrid, 2000.

' Para Maíno sigue siendo fundamental la obra de Angulo, D. y Pérez Sánchez, A.E., Historia de la Pintura Española. Escuela Madrileña del primer tercio del siglo XVII, CSIC, Madrid, 1969. Más recientemente véase Papi, G., «Proposte per Juan Bautista Maíno» en Studi di Storia dell'Arte, 3, Todi, 1993 y Boitani, M.C., Juan Bautista Maíno. Relazione sulla vita, le opere i miracoli compiuti in pittura da un «lucidísimo ingenio» e su coloro che ne hanno scritto, Roma-Fratelli Palombi Editori, 1995. Finalmente las aportaciones de Pérez Sánchez, A.E. «Fray Juan Bautista Maíno, pintor Dominico» en Arte Cristiana, 764-765, 1994, pp. 433-442 y del mismo autor «Sobre Juan Bautista Maíno» en Archivo Español de Arte, 278, 1997, pp. 113-125. Para las fuentes documentales, las aportaciones de Marías, F., «Juan Bautista Maíno y su familia» en Archivo Español de Arte, 1976 y Cortijo Ayuso, F., «El pintor Juan Bautista Maíno y su familia» en Wad-Al-Hayara, 5, 1978.

${ }^{2}$ Martínez, J., Discursos practicables del nobilísimo arte de la pintura, ed. de 1866, p. 120

${ }^{3}$ Navarrete Prieto, B., «La Magdalena en la pintura española del Siglo de Oro» en María Magdalena: éxtasis y arrepentimiento, cat. exp. Comisariada por Odile Delenda, Museo Nacional de San Carlos de México, 2001, pp. 48-63.

${ }^{4}$ Hollstein, F.W.H., Dutch and Flemish Etchings, engravings and woodcuts, XLIII, Lucas Vosterman I, Netherlands, $1993, n^{\circ} 90$, p. 87.
} 
que representa a la santa pecadora, pudo suministrar al pintor dominico la composición de la obra con la santa echada y con la calavera en primer término.

El objeto de la presente nota es dar a conocer una nueva versión de la Magdalena Penitente de Maíno ${ }^{5}$, que estuvo en la colección de los Vizcondes de Roda (Fig. 1), en este caso de formato vertical, y presentando a la Santa en completo ensimismamiento, con un libro sagrado en la mano, el tarro de perfume a su izquierda y con los ropajes ricos de terciopelo rojo con gran costurón, caídos, dejando al descubierto un seno y con la hermosa cabellera rubia que le cae por los hombros en imagen turbadora. A la derecha una cruz broncínea, clavada en el suelo, ante un paisaje con cascada de un gran refinamiento en la ejecución; en primer término la calavera y a la izquierda el flagelo y un libro. Lo interesante es señalar que esta obra es versión autógrafa - y de excelente calidad - de otra que estuvo en una colección particular de Vitoria (Fig. 2) -y que estudiamos y reprodujimos como de Maíno- en el catálogo citado de México ${ }^{6}$. Esta obra presentaba en su lado lateral derecho un corte limpio, así como en su parte inferior, por lo tanto, no contenía al crucificado y la cascada del fondo, ni tampoco la vegetación a los pies de la santa ni la calavera, como si con el corte se tratara de eliminar toda alusión al carácter religioso de la imagen.

Podemos señalar ahora el modo como Maíno afrontó estas dos composiciones. No ha sido señalada hasta ahora ninguna fuente tan directa para interpretar la obra del pintor dominico, y, en este caso, no ofrece duda alguna que el grabado de Johan Sadeler I de La Magdalena (Fig. 3) es la fuente seguida directamente por el pintor. Maíno se concentra en la imagen de la Santa, en la cueva y la cascada del fondo, en el Crucificado, la calavera y en el ungüentario y libro que está leyendo, así como en el flagelo a sus pies. Todos estos elementos aparecen en la versión ahora dada a conocer y en la otra, al estar cortada, quedaron eliminados la calavera, el crucificado y la vegetación, que es interpretada por Maíno con gran maestría, con detalles en las hojas de vid e incluso de un caracol en primer término. El rosario que lleva la santa en la mano en la estampa es el único elemento que Maíno no incorpora en sus versiones.

Con respecto al modelo de la Santa y como se trata su desnudez, aunque depende de Sadeler, está reinterpretada con sensualidad extrema, así como la coloración lechosa de su cuerpo, la calidad de sus ropajes o el tipo de ungüentario de plata, similar en las dos versiones y, sin embargo, más modesto en la estampa. Es este ejemplo, que damos a conocer, excelente pretexto para reflexionar acerca del desnudo en la España del siglo de Oro. Javier Portús, en sus inteligentes apreciaciones en este sentido, no hallaba indecencia o erotismo en este tipo de representaciones donde la Magdalena u otros santos mostraban su desnudez en su arrepentimiento. Dice Portús que «la sociedad española admiraba la mortificación y la alentaba por su utilidad para estimular el sentimiento religioso» ${ }^{8}$, por lo tanto no procedería pensar en este tipo de obras - para Portús - en una lectura que fuera más allá del sacramento de la Penitencia.

\footnotetext{
${ }^{5} 1$ '60 x 1,24. Óleo sobre lienzo.

${ }^{6}$ La Magdalena Penitente, que atribuimos en nuestro texto de la exposición de México a Maíno, compareció en subasta pública en Edmun Peel y Asociados, Pintura antigua y del siglo XIX, Madrid, 30 octubre, 1990, lote, 12 como «Seguidor de Caravaggio, hacia 1620», 114 x 78,5 cms. Esta obra fue estudiada como «anónimo italiano» en el catálogo Mirari. Un pueblo al encuentro del arte, Vitoria, 1989, p. 314 cat. 45. En estos momentos se hallaba en una colección particular de Vitoria y como se evidencia en el catálogo se encontraba bastante sucia. En esta ficha Fernando Tabar de Anitua aventura como autor del lienzo a Luigi Miradori el Genovesino, tras considerar otras atribuciones a diversos pintores italianos. Volvió a comparecer en subasta en Old Masters Pictures, Christie's Londres, 9 de Julio de 1999, lote 71, ya con correcta atribución a Maíno y tras una limpieza bastante drástica.

${ }^{7}$ Bartsch, A., The Illustrated Bartsch, Johan Sadeler I, $\mathrm{n}^{\circ} 7001$.

${ }^{8}$ Portús Pérez, J., «Indecencia, mortificación y modos de ver» en Morán Turina, M. y Portús Pérez, J., El Arte de mirar. La pintura y su público en la España de Velazquez, Madrid, 1997, pp. 250 y ss.
}

AEA, LXXVI, 2003, 304, pp. 407 a 436 


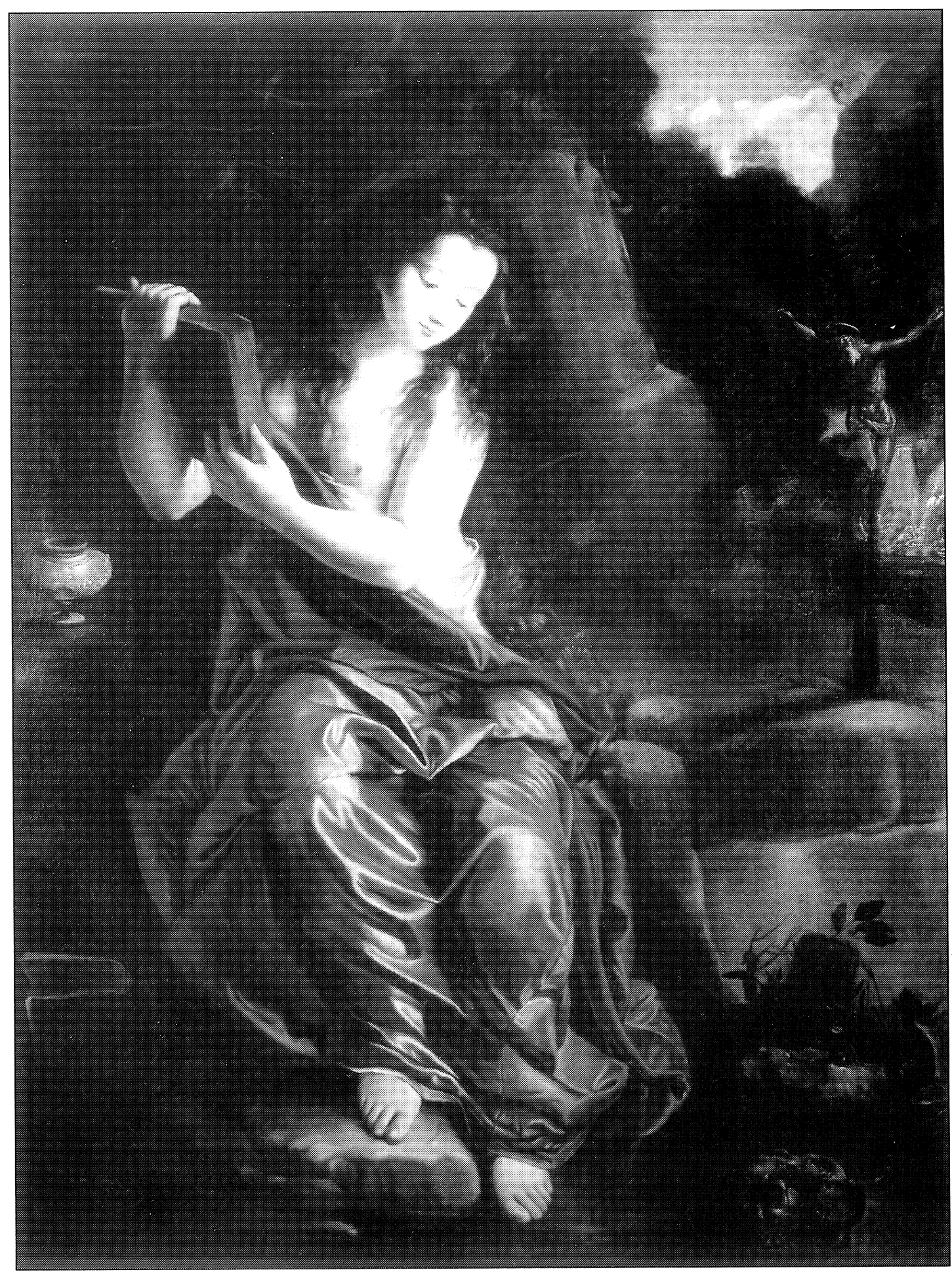

Fig. 1. Juan Bautista Maíno, Magdalena penitente, procedente de la Col. Vizcondes de Roda. 

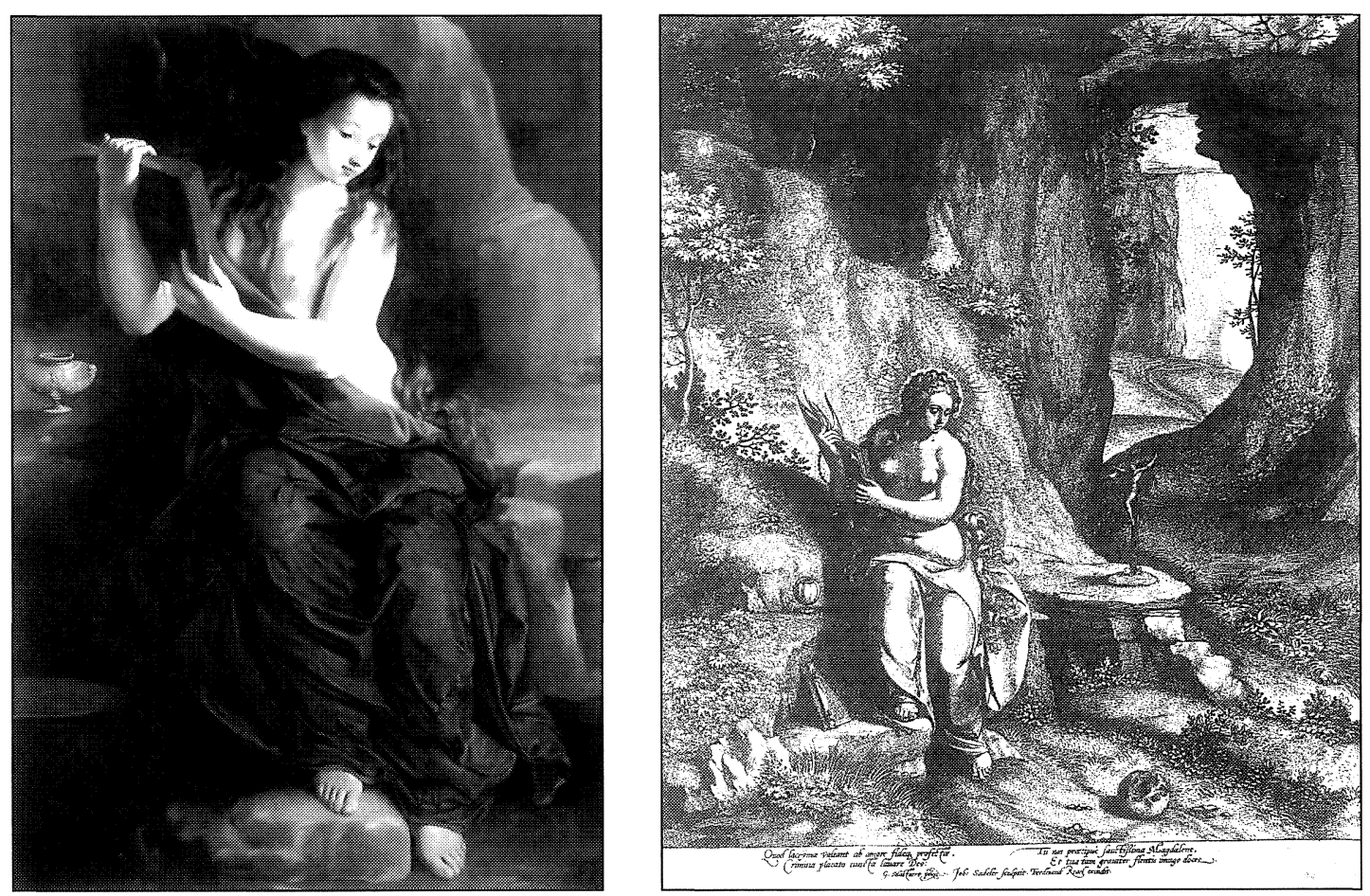

Fig. 2. Juan Bautista Maíno, Magdalena penitente, óleo sobre lienzo, Col. particular. Fig. 3. Johan Sadeler I, La Magdalena penitente, grabado.

Incidiendo en el testimonio de Portús, valdría la pena citar el documento aportado por José Luis Barrio Moya ${ }^{9}$, quien al estudiar el inventario de bienes del canónigo de Granada Don Juan de Matute en 1629, que había estado en Italia, cita como de Maíno «un quadro entero de la Magdalena en el desierto» calificándolo de muy alta pintura, y que ineludiblemente habría que relacionarlo con cualquiera de las dos versiones estudiadas.

Valga este ejemplo como testimonio — nuevamente - del modo de proceder de nuestros artistas y, sobre todo, como de una estampa, en esta ocasión de Sadeler, con el modelo marcado de antemano, el pintor concentra toda su carga de realidad en el cuerpo desnudo de La Magdalena, interpretado en estas dos pinturas con una maestría, delicadeza y verosimilitud asombrosas.

Benito Navarrete Prieto

Universidad de Alcalá

\footnotetext{
${ }^{9}$ Barrio Moya, J.L., «La colección pictórica de Don Juan de Matute, canónigo de la Catedral de Granada (1628)» en Revista del Centro de Estudios Históricos de Granada y su Reino, 5, Granada, 1991.
}

AEA, LXXVI, 2003, 304, pp. 407 a 436 